\title{
Ectopic Pancreas Tissue in the Gallbladder: An Incidental Mass in Laparoscopy
}

\author{
Hüseyin Özden, $\mathrm{MD}^{1^{*}}$; Muhammed Gömeç, MD²; Olcay Kurtulan, $\mathrm{MD}^{3}$ \\ ${ }^{1}$ Ahi Evran University Faculty of Medicine Department of General Surgery, Kırşehir, Turkey \\ ${ }^{2}$ Merzifon Karamustafa Paşa State Hospital Department of General Surgery, Amasya, Turkey \\ ${ }^{3}$ Hacettepe University Faculty of Medicine Department of Pathology, Ankara, Turkey
}

\begin{abstract}
Ectopic pancreatic tissue (EPT) is a congenital pancreatic tissue located in a location other than the normal anatomical site of the pancreas. It is usually asymptomatic and can be detected during surgical procedures or postoperatively in pathology examinations. The importance of EPT is the possibility of malignant transformation, although rare. It can mimic malignant masses. Since preoperative diagnosis is often unlikely, resection is the preferred method. We report a case with gallstones who underwent elective cholecystectomy. EPT was detected in the gallbladder.

Keywords: Ectopic pancreatic tissue, Gallbladder, Incidental mass

Cite this article as: Özden H, Gömeç M, Kurtulan O. Ectopic pancreas tissue in the gallbladder: an incidental mass in laparoscopy. Arch Iran Med. 2020;23(11):761-763. doi: 10.34172/aim.2020.100.
\end{abstract}

Ocotober 3, 2019, Accepted: September 6, 2020, ePublished: November 1, 2020

\section{Introduction}

Ectopic pancreatic tissue (EPT) is a pancreatic tissue congenitally located in a location other than the normal anatomical site of the pancreas. EPT is a developmental disorder of unknown cause. Its histology has similar features with the main pancreas tissue. The main pathology is that the tissue is not in its normal location and has no connection with the main pancreatic tissue. It can be encountered anywhere in the gastrointestinal tract. Most cases are asymptomatic. The prevalence of the condition was found to vary between $0.5 \%$ to $13.7 \%$ in an autopsy study. It has been found to be more common in gastrectomy cases in general (in cases diagnosed intraoperatively) and it is estimated that it is encountered by chance in $0.9 \%$ of the cases. ${ }^{1,2}$ Definitive diagnosis can be made after resection and histopathologic examination of the mass that is encountered preoperatively or intraoperatively.

\section{Case Report}

A 57-year-old male patient presented with recurrent abdominal pain in the right upper quadrant. He had abdominal distention, indigestion and dyspeptic complaints. He had a history of episodes of cholecystitis. On physical examination of the patient, nonspecific tenderness was found localized to the right upper quadrant of the abdomen. All parameters were normal in laboratory evaluation. Abdominal ultrasonography revealed multiple gallstones, the largest of which was $2 \mathrm{~cm}$ in diameter and gallbladder wall thickness suggesting cholecystitis. The patient underwent laparoscopic cholecystectomy.
Macroscopically, the gallbladder wall thickness was seen to be increased asymmetrically. The specimen was sent for histopathologic examination. The patient was followed up and discharged in good health. The patient demonstrated good general conditions during long-term follow-up.

Microscopic examination revealed brown peritoneal material with an irregular surface measuring $5.5 \times 3 \times 1.8$ $\mathrm{cm}$. Sludge was present in the gallbladder and one yellow stone measuring $2 \mathrm{~cm}$ in diameter was removed. The inner surface of the sac was coarsely trabecular and gallbladder wall thickness was measured as $0.8 \mathrm{~cm}$ at its thickest point. A creamy nodular pale lesion measuring $1.5 \times 1.3 \times 0.8$ $\mathrm{cm}$ was found on the wall of the corpus of the gallbladder. Multiple sections were taken for analysis and the lesion was found to be EPT with chronic pancreatitis (Figure 1). The remaining tissue was consistent with chronic cholecystitis (Figure 2).

\section{Discussion}

Ectopia can be defined as a state where an organ is located somewhere in the body other than the place where it should normally be found. EPT is a rare anomaly mostly found in the stomach and duodenum. Histopathological classification of three types for EPT was first described by Heinrich in 1909. Type 1 contains acini, canal and islet cells, similar to normal pancreatic tissue. This type is the most common. The other two types have acini or channel dominance. ${ }^{3}$ In the case presented here, the EPT was found to be compatible with type 1 since it contained all the features of normal pancreatic tissue. This system 


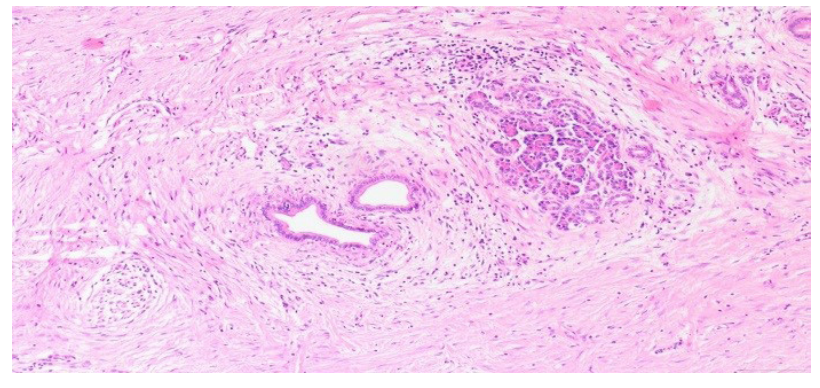

Figure 1. There was a microscopic rest of heterotopic pancreatic tissue, composed of exocrine pancreatic acini in the submucosallayer of the gallbladder wall (H\&E x100).

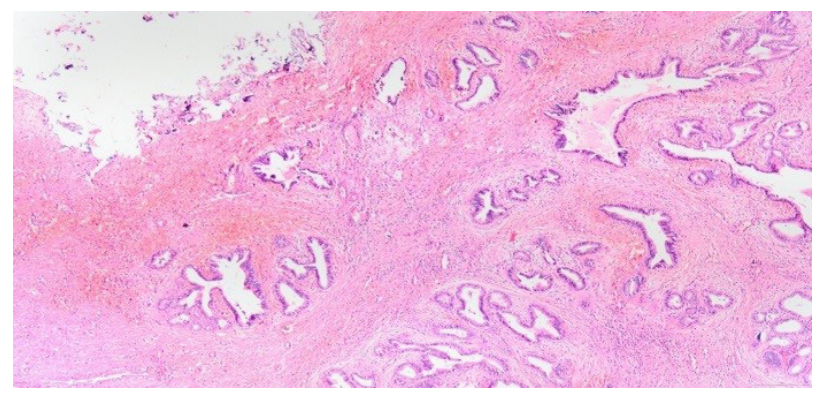

Figure 2. On microscopic examination, ulceration, glandular hyperplasia and chronic cholecystitis are seen in the mucosal layer of the gallbladder (H\&E x40).

was modified by Fuentes in 1973 when a fourth type, consisting of islet cells alone, was identified ${ }^{3}$ (Table 1).

Gallbladder is very rarely involved by ectopic pancreas. ${ }^{4,5}$ The first reported case of heterotopic pancreas in the gallbladder dates back to $1916 .{ }^{6}$ Different theories have been proposed for the origin of this abnormal tissue. The most widely accepted hypothesis is that the tissue is separated from the pancreas during the rotation of the gastrointestinal tract during the embryonic period. ${ }^{6}$

Endoscopic methods and sampling by biopsy for diagnostic purposes are helpful for definitive diagnosis in cases when symptoms arise due to the EPT located in viscera with a lumen. ${ }^{7}$ However, patients with gallbladder diseases are generally operated on due to specific clinical requirements such as gallstones and/or cholecystitis, and therefore the true diagnosis is established by postoperative histopathological examination. Magnetic resonance imaging (MRI) performed in case of clinical and radiographic suspicion or incidentally may aid in preoperative diagnosis. EPT is seen as the main pancreas in T1-weighted MRI images; thus, this modality can be used for differential diagnosis from other lesions. ${ }^{8,9}$

Although heterotopic pancreatic tissue is diagnosed incidentally in general, it has the potential for development of all metaplastic and neoplastic changes that occur in the main pancreatic tissue such as acute or chronic pancreatitis, cyst formation, calcification, pancreatic cancer and endocrine tumors. ${ }^{10}$ In our case, signs of pancreatitis were observed in the EPT. Gallstones were also present and signs of cholecystitis were detected. EPT may present with different symptoms depending on its location. For example, Saeed et al reported a case of intussusception which was caused by EPT detected in the jejunum. ${ }^{11}$ In another study, heterotopic pancreatic tissue in the duodenum was found to cause stenosis of the duodenum. ${ }^{12}$ EPT in the esophagus, like other esophageal lesions, can often cause dysphagia and epigastric pain and sometimes gastroesophageal reflux and nausea. ${ }^{13}$

Malignant transformation of EPT is very rare and has been reported to occur in $0.7 \%$ to $1.8 \%$ of all cases. ${ }^{14,15}$ In the literature, malignancy was reported to develop in EPT in 52 cases. ${ }^{16}$ Therefore, complete excision of the incidentally found pancreatic tissue is the treatment of choice. Because there are very few reported cases, clinical and radiological features are not well defined. Preoperative diagnosis of this rare finding is not possible due to nonspecific features and definitive diagnosis is possible only by histopathological examination.

In conclusion, if a focal mass is identified in the gallbladder, EPT should be kept in mind. Although the ectopic pancreas is usually asymptomatic, the risk of development of malignancy necessitates resection of this tissue when diagnosed.

\section{Authors' Contribution}

HÖ: General writing of the article, design, surgery stage; MG: Literature review, design, surgery stage; OK: Data analysis, pathology stage.

\section{Conflict of Interest Disclosures}

The authors report no conflicts of interest.

\section{Ethical Statement}

Ethical principles were followed for case presentation. Patient identification information was kept confidential.

Table 1. Heterotopic Pancreatic Tissue Types

\begin{tabular}{lll}
\hline Heterotopic Pancreas Type & Histologic Features Described by Heinrich & Histologic Features Described by Fuentes \\
\hline Type 1 & $\begin{array}{l}\text { Heterotopic tissue consists of all the components of normal } \\
\text { pancreatic tissue, including acini, ducts, and islet cells }\end{array}$ & $\begin{array}{l}\text { Heterotopic tissue consists of all the components of } \\
\text { normal pancreatic tissue, including acini, ducts, and islet } \\
\text { cells }\end{array}$ \\
\hline Type 2 & Heterotopic tissue consists of acini and ducts, with no islet cells & Heterotopic tissue consists of ducts only \\
Type 3 & Heterotopic tissue consists of ducts only & Heterotopic tissue consists of acini only (exocrine) \\
Type 4 & - & Heterotopic tissue consists of islet cells only (endocrine) \\
\hline
\end{tabular}




\section{References}

1. Kung JW, Brown A, Kruskal JB, Goldsmith JD, Pedrosa I. Heterotopic pancreas: typical and atypical imaging findings. Clin Radiol. 2010;65(5):403-7. doi: 10.1016/j. crad.2010.01.005.

2. Wei R, Wang QB, Chen QH, Liu JS, Zhang B; Upper gastrointestinal tract heterotopic pancreas: findings from CT and endoscopic imaging with histopathologic correlation. Clin Imaging. 2011;35(5):353-9. doi: 10.1016/j. clinimag.2010.10.001.

3. Trifan A, Târcoveanu E, Danciu M, Huțanaşu C, Cojocariu C, Stanciu C. Gastric heterotopic pancreas: an unusual case and review of the literature. J Gastrointestin Liver Dis. 2012;21(2):209-12.

4. Bau PC, Lucchese A, Hohmann FB, Da Silva VD, Marcal JM. Ectopic pancreatic tissue in a gallbladder. SOJ. 2016;3(3):1-2.

5. Al-Shraim M, Rabie ME, Elhakeem H, Kandeel A, Shah MT, Jamil S. Pancreatic heterotopia in the gallbladder associated with chronic cholecystitis: a rare combination. JOP. 2010;11(5):464-6.

6. Marcano AJL, Gonzales JD, Ramia JM, Alonso S, Kuhnhardt A, Perna C, et al. Heterotopic pancreatic tissue in gallbladder. Arch Clin Exp Surg. 2016;5(4):250-253. doi: 10.5455/ aces. 20151012123519.

7. Shinji Endo, Rie Saito, Daisuke Ochi, Takeshi Yamada, Mitsuaki Hirose, Yoshinori Hiroshima, et al. Effectiveness of an endoscopic biopsy procedure using EUS-FNA and EMR-C for diagnosing adenocarcinoma arising from ectopic pancreas: two case reports and a literature review. Intern Med. 2014;53(10):1055-62. doi: 10.2169/ internalmedicine.53.1420.

8. Kung JW, Brown A, Kruskal JB, Goldsmith JD, Pedrosa I. Heterotopic pancreas: typical and atypical imaging findings. Clin Radiol. 2010;65(5):403-7. doi: 10.1016/j. crad.2010.01.005.

9. Okuhata $\mathrm{Y}$, Maebayashi T, Furuhashi S, Abe K, Takahashi $\mathrm{M}$, Kanamori N, et al. Characteristics of ectopic pancreas in dynamic gadolinium-enhanced MRI. Abdom Imaging. 2010;35(1):85-7. doi: 10.1007/s00261-008-9491-6.

10. Filip R, Walczak E, Huk J, Radzki RP, Bieńko M. Heterotopic pancreatic tissue in the gastric cardia: a casereportandliteraturereview. World J Gastroenterol. 2014;20(44):16779-81. doi: 10.3748/wjg.v20.i44.16779.

11. Saeed MF, Verhagen KR, Albinali S, Juma IM. A case report and literature review: incidental jejunal ectopic pancreatic tissue in an emergency bowel exploration for suspected intussusception. AME Case Rep. 2019;3:24. doi: 10.21037/ acr.2019.07.05.

12. Gökhan Karaca, Adnan Tas, Recep Pekcici, Hüseyin Özer, Seyfettin Köklü; Unusual Cause of Severe Nauseaand Vomiting in an Elderly Man: Heterotopic Pancreas. Int J Gerontology. 2011;5(2):133-4. doi: 10.1016/j.ijge.2011.04.007

13. Ulrych J, Fryba V, Skalova H, Krska Z, Krechler T, Zogala D. Premalignant and malignant lesions of the heterotopic pancreas in the esophagus: a case report and review of the literature. J Gastrointestin Liver Dis. 2015;24(2):235-9. doi: 10.15403/jgld.2014.1121.242.uly.

14. Makhlouf HR, Almeida JL, Sobin LH. Carcinoma in jejuna pancreatic heterotopia. Arch Pathol Lab Med. 1999;123(8):70711. doi: 10.1043/0003-9985(1999)123<0707: $\mathrm{CIJPH}>2.0$. $\mathrm{CO} ; 2$.

15. Guillou L, Nordback P, Gerber C, Schneider RP. Ductal adenocarcinoma arising in a heterotopic pancreas situated in a hiatal hernia. Arch Pathol Lab Med. 1994;118(5):568-71.

16. Kaneko T, Ohara M, Okamura K, Fujiwara-Kuroda A, Miyasaka $\mathrm{D}$, Yamabuki T, et al. Adenocarcinoma arising from an ectopic pancreas in the duodenum: a case report. Surg Case Rep. 2019;5(1):126. doi: 10.1186/s40792-019-0684-8. 